\title{
The Proto-Oncoprotein c-Cbl Protects Cells against Oxidative Stress by Down- Regulating Apoptosis and is Highly Expressed in Several Cancers
}

Sadok Yakoub ${ }^{1,2}$, Nisrine El-Chami ${ }^{1,3}$, Krisztian Kaszas ${ }^{1,4}$, Mouhannad Malek ${ }^{1,5}$, Mohamed El Sirkasi ${ }^{6}$, Colin A. Smith ${ }^{3}$, Elias Baydoun ${ }^{3}$, Eric Tabone $^{7}$, Serge N Manié ${ }^{1,8}$ and Daniel CL Régnier ${ }^{1 *}$

${ }^{1}$ Cancer Research Center INSERM UMR 1052 CNRS5286, Léon Bérard Center (CLB), Lyon, France

${ }^{2}$ CNRS UMR 7054 Surgery Research Center, Medicine Faculty, Henri-Mondor Hospital, Créteil, France

${ }^{3}$ Biology Department, American University of Beirut, Beirut, Lebanon

${ }^{4}$ Assay Automation and Data/Compound, Management Innovation \& Discovery, Crucell Vaccine Institute Archimedesweg 4-6, 2333 CN Leiden, Netherlands

5 Inositide Laboratory-Signaling program, Babraham Institute, Babraham Research campus, Babraham, Cambridge, United Kingdom

${ }^{6}$ Laboratory Department, Higher Medical Institute, Misurata - Libya

${ }^{7}$ Laboratoire d'Anatomie et de Cytologie pathologiques, Centre Léon Bérard, Lyon, France

${ }^{8}$ University of Lyon1, F-69000 Lyon, France

\begin{abstract}
Objective: To determine the role of $\mathrm{c}-\mathrm{Cbl}$ in the apoptotic process, using several means, stressing the role of oxidative stress in cancer cells.

Methods: Prostatic epithelial cell apopotosis of c-Cbl-/-mice were compared to wildtype mice (n: 6 per condition), upon testosterone-antagonist flutamide. c-Cbl-deficient mouse embryonic fibroblasts (MEFs) were compared to wild type MEFs under etoposide or hydrogen peroxide treatments. The use of c-Cbl RNA silencing in the human prostate adenocarcinoma cell line LNCaP allowed to reveal c-Cbl's role in LNCaPs' apoptosis. The role of the p38-MAPK stress pathway in the LNCAP c-Cbl anti-apoptotic effect as well as its relationship with the well-documented Grb2-associated Tyrosine-Kinase-Receptor (TKR) down-regulation were investigated, using $\mathrm{c}-\mathrm{Cbl}$ and/or Grb2 RNA silencing. Human c-Cbl protein expression was analysed by Western blotting and immunostaining, comparing prostatic adenocarcinoma (x22) to benign prostatic hypertrophia (x6). In situ tissue microarrays were used to assess several human malignancies ( $x 17$ and $x 6$ spots/tissue) and to compare the magnitude of c-Cbl and oxidative stress expression.
\end{abstract}

Results: the cellular apoptotic threshold decreased in Mouse c-Cbl-/-prostatic cells and c-Cbl-/- MEFs. Only hydrogen peroxide in c-Cbl-/-MEFs induced apoptosis up to six times more than controls. Similar results were found in LNCaPs. c-Cbl down-regulates the activation of the apoptotic ASK1-p38MAPK stress pathway. c-Cbl is overexpressed in prostate, ovary, uterus, brain, lung, colon, rectum adenocarcinoma and in rhabdomyosarcoma. We found a correlation between malignant oxidative stress and c-Cbl over-expression.

Conclusions: $\mathrm{c}-\mathrm{Cbl}$ increases the cellular apoptotic threshold of wild type MEFs and mouse prostate cells. $\mathrm{c}-\mathrm{Cb}$ behaves as a strong cellular protector against oxidative stress in MEFs and LNCaPs. The p38-MAPK pathway is down-regulated by c-Cbl, possibly independently of the Grb2-associated TKR down-regulation. A high c-Cbl expression in several cancers often associated with high oxidative stress expression has been found, suggesting that $\mathrm{c}-\mathrm{Cbl}$ could thereby promote their survival.

Keywords: Proto-oncoprotein c-Cbl; Malignant cell; Apoptosis; Oxidative stress; MAPK Stress pathway

\section{Introduction}

The proto-oncoprotein c-Cbl controls several down-regulation signals leading to degradation of tyrosine-kinase receptors (TKR) [1-3] or endocytic trafficking $[1,4,5]$. It interacts with numerous signalling proteins through their Src homology-2 or -3 (SH2 or $\mathrm{SH} 3)$ domains $[6,7]$. Several groups, including ours, have reported an association between down-regulation of apoptosis and c-Cbl. First, oncogenic forms of c-Cbl are anti-apoptotic [8]. The pro-apoptotic Bim EL BH3only protein has been shown to be down-regulated by c-Cbl in primary culture of osteoclastes [9]. We found a similar, though probably indirect, regulation of BimEL through c-Cbl in mouse testicular germ cells and extended these findings to the pro-apoptotic factor Smac/ DIALO [10], indicating that c-Cbl likely exerts an anti-apoptotic effect. Langdon et al. reported that a c-Cbl RING finger mutant leads to thymocyte apoptosis and to an unexpected Akt activation, as well as an increase expression of Bim EL [11,12]. Sproul et al., using PC12 cells and primary cultures of neurons [13], reinforced the anti-apoptotic effect of $\mathrm{c}$-Cbl, reporting that $\mathrm{c}$-Cbl inhibits the ability of mixed- lineage kinase (MLK), from the mitogen-activated protein (MAP) kinase family, to activate c-Jun $\mathrm{N}$-terminal kinase (JNK). Finally, it has been reported that $\mathrm{c}-\mathrm{Cbl}$ regulates the degradation of the pro-apoptotic TRAIL receptors $[14,15]$ and that the TRAIL/MEKK4/HSP27/Akt survival network is modulated by the Src/CIN85-c-Cbl complex [16].

Nonetheless, based on its dominant role in growth factor receptor

*Corresponding author: Daniel CL Régnier, Cancer Research Center, UMR 5286 CNRS U1052 INSERM, CLB, Cheney D, 28 rue Laënnec, 69008 Lyon, France, Tel: (33)629468606, (33)474854512; Fax: (33)(0)469166660; E-mail: dclregnier@gmail.com

Received February 16, 2014; Accepted March 27, 2014; Published March 31, 2014

Citation: Yakoub S, El-Chami N, Kaszas K, Malek M, El Sirkasi M, et al. (2014) The Proto-Oncoprotein C-Cbl Protects Cells against Oxidative Stress by DownRegulating Apoptosis and is Highly Expressed in Several Cancers. J Cancer Sci Ther 6: 122-135. doi:10.4172/1948-5956.1000260

Copyright: ( 2014 Yakoub S, et al. This is an open-access article distributed under the terms of the Creative Commons Attribution License, which permits unrestricted use, distribution, and reproduction in any medium, provided the original author and source are credited. 
down-regulation and its anti-survival aspect [1-3], the commonly accepted view has been that the E3-Ubiquitine ligase c-Cbl would function as a pro-apoptotic modulator, and not as an anti-apoptotic one [17-20]. Therefore, it is important to establish more clearly the regulation of apoptosis exerted by c-Cbl in somatic cells and its consequence in cancer. Considering that alteration of programmed cell death is the main explanation for the gradual accumulation of human cancer cells [21,22], and that c-Cbl over-expression has been recently observed in human prostate adenocarcinoma [23], the elucidation of the role of $\mathrm{c}-\mathrm{Cbl}$ in malignant cell apoptosis is of obvious importance, especially if c-Cbl is over-expressed.

Herein, we report that $\mathrm{c}-\mathrm{Cbl}$ is anti-apoptotic based on several approaches: in vivo experiments with prostatic cells, ex vivo experiments through the study of mouse embryonic fibroblasts (MEFs), and in vitro experiments with human prostate adenocarcinoma cell lines (LNCaP). We demonstrate that $\mathrm{c}-\mathrm{Cbl}$ acts as a cell protector against oxidative stress (ex vivo and in vitro experiments) and that this process follows the Apoptosis Signal-regulating Kinase-1-p38MAPK (ASK1-p38MAPK) stress pathway. Based upon preliminary experiments, we suggest that this effect is independent of the well-known Grb-2 associated TKR down-regulation effect. We show that $\mathrm{c}$-Cbl is over-expressed in several types of human cancer and appears to correlate with ROS expression, which reinforce an active role for $\mathrm{c}-\mathrm{Cbl}$ in malignant cell survival. These results suggest interesting diagnostic and therapeutic opportunities.

\section{Material and Methods}

\section{Ethic statements}

All studies on animals were conducted in accordance with current regulations of ALECS - Lyon approved by the INSERM/CNRS animal care committee (France). The human material (frozen tissues and slides) was furnished by the laboratory of Anatomy-Pathology in LyonSud hospital (Pr. F. Berger, Dr. M. Decaussin). All prostate tumours and benign prostate hypertrophy (BPH) were collected from patients treated in the Lyon-Sud hospital within the "Hospices Civils de Lyon", with informed consent from all participants involved in this study. The consent obtained from each participant was written, in accordance with the current regulation approved by the "Hospices Civils de Lyon" and by the INSERM/CNRS ethic committee (France).

\section{Animal origins and manipulations}

The c-Cbl knock-out (KO) mice constructed from sv129 WT mice were generously provided by $\mathrm{Dr} \mathrm{Hua} \mathrm{Gu}$ and Dr Naramura [24]. Male Sprague-Dawley rats of 60 days old were obtained from IFFA Credo (L'Abresle, France). The mice were decontaminated and housed in ALECS module SPF in Lyon, France and used for in vivo experiments at 10 weeks of age. The anti-androgen treatment consisted of vehicle control (methylcellulose) with or without $25 \mathrm{mg} / \mathrm{kg} /$ day (mice) or 10 $\mathrm{mg} / \mathrm{kg} /$ day (rats) of flutamide and was administrated by daily gavages for four days. Six to ten animals were used per experimental condition. Castration experiments were performed on rats (60 days old) under pentobarbital anaesthesia $(60 \mathrm{mg} / \mathrm{kg}$ body $\mathrm{wt})$.

\section{Genotyping mice/mouse embryos using PCR}

For genotyping mice/mouse embryos, genomic DNA was isolated from the 13.5 day-old embryos as described [25]. Genomic DNA was isolated from the13.5 days-old embryos. Limbs were digested in Tailbuffer (50 mM Tris pH 8.0-100 mM EDTA-100 mM NaCl-1\% SDS) using proteinase $\mathrm{K}$ for $4 \mathrm{~h} @ 55^{\circ} \mathrm{C}$. DNA was extracted by phenolchloroform and the genotype of embryos was verified using PCR. Two sets of primers were used [24]:

\section{cbl-10 (GACGATAGTCCCGTGGAAGAGCTTTCGACA),}

cbl-11 (CCTAAGTGGTAGGATTATAATTGCAAGCCACCAC) to detect $\mathrm{WT}^{\mathrm{c}-\mathrm{Cbl}}$,

\section{and cbl-13 (TCCCCTCCCCTTCCCATGTTTTTAATAGACTC)}

and loxP (TGGCTGGACGTAAACTCCTCTTCAGACCTAATA$\mathrm{AC}$ ) to detect $\mathrm{KO}^{\mathrm{c}-\mathrm{Cbl}}$, producing 273bp and 306bp PCR products, respectively. The PCR program used was as follows: 3 x [ 94 C 3' - $60 \mathrm{C}$ 2' $\left.-72 C 1^{\prime}\right]-30 \times$ [ $\left.94 C 1^{\prime}-60 C 1^{\prime}-72 C 1^{\prime}\right]-1 \times\left[94 C 1^{\prime}-60 C\right.$ 1' - 72 C 10'].

\section{Cells, culture conditions and experiment analysis}

Mouse embryos (13.5 day-old) from c-Cbl+/- mating were used to obtain primary mouse embryonic fibroblasts (MEFs) then cultured according to established protocols [26,27]. Cells were seeded $24 \mathrm{~h}$ before the start of the treatment $\left(10^{5}\right.$ cells in $1 \mathrm{~mL}$ cell culture medium/ well), etoposide added to final concentration from 1 to $30 \mu \mathrm{M}$ and $\mathrm{H}_{2} \mathrm{O}_{2}$ from $50 \mathrm{nM}$ to $100 \mu \mathrm{mM}$. Cells were lysed for protein extraction 16 to $24 \mathrm{~h}$ after treatment, followed by western blot, TUNEL experiments or collected using Cytospin (10'@800 g) for 4'-6 diamino-2-phenylindole (DAPI) staining.

For western blotting, prostatic tissue was homogenized in $200 \mathrm{ml}$ of ice-cold hypotonic buffer ( $25 \mathrm{mM}$ Tris- $\mathrm{HCl}$ ( $\mathrm{pH} 7.4)$ and proteaseinhibitor cocktail). Tissues were further homogenized by sonication (10 sec). Protein concentration was determined by the Bradford assay. Proteins (100 mg) were resolved on $10 \%$ SDS/polyacrylamide gels and electrophoretically transferred to nitrocellulose membranes using CAPS buffer (13, pH 11) containing 20\% methanol at a constant voltage of $100 \mathrm{~V}$ for $60 \mathrm{~min}$. Following transfer, the membrane was incubated in TBS containing $10 \%$ fat-free dry milk and $0.1 \%$ Tween-20 for $2 \mathrm{~h}$ at room temperature. The membrane was rinsed three times with TBS/0.1\% Tween-20 (three times for $10 \mathrm{~min}$ each) and then incubated with the first antibody (in TBS containing 2\% fat-free dry milk) overnight at $48^{\circ} \mathrm{C}$. The antibody concentrations were used following the manufacturer's instructions (1:100 procaspase- 6 , cleaved caspase- 9 and cleaved caspase 3; 1:200 BimEL, Smac/DIABLO, Bak, IAPs, c-Cbl, Bax antibodies). The membrane was then rinsed with TBS/0.1\% Tween-20 (three times for $10 \mathrm{~min}$ each) and incubated with horseradish peroxidase labeled anti-rabbit IgG (1:2500) or antigoat IgG (1:2000) in TBS containing $2 \%$ fat-free dry milk and $0.1 \%$ Tween-20 for $1 \mathrm{~h}$ at room temperature. The membrane was thoroughly washed with TBS/0.1\% Tween-20 (three times for 10 min each) and then with TBS. Bound antibodies were detected by chemiluminescence using a CovalAb detection kit and Biomax MR Films. The protein loading was checked by reprobing the blot with a rabbit IgG antiactin (1:500). Western blots were processed identically, and comparison of protein expression used bands from the same gel.

Antibodies used: western blot experiments were done with the following primary antibodies purchased from several manufacturers as indicated. From Santa Cruz Biotechnology: anti-Cbl (C-15), antiBim EL (H-191), anti-Bcl-2 (N-19), anti-c-IAP1 (H-83), anti-c-IAP2 $(\mathrm{H}-85)$ rabbit polyclonal antibodies and anti-Bax $(4 \mathrm{H} 32)$ mouse monoclonal antibody. Anti-XIAP (ab21278) and anti-apurinic/ apyrimidinic endonuclease (APE1/REF1) human fusion protein (ab82) 
polyclonal antibodies were obtained from Abcam. Cleaved caspase-3 (5AE1) rabbit monoclonal antibody was obtained from Cell Signaling Laboratories as well as MLK3, ASK1, p38MAPK and phospho (Thr180/ Tyr182)-p38MAPK polyclonal antibodies.

For DAPI staining, cells were fixed in 3:1 solution Ethanol: Acetic acid $10 \mathrm{mn}$, stained with DAPI- $\mathrm{NaCl} 0.9 \%(0.4 \mu \mathrm{g} / \mathrm{mL}$ final $) 30 \mathrm{~min}$ at RT. The cells undergoing apoptosis were evaluated using DAKOs fluorescent mounting medium by nuclear shrinkage or apoptotic bodies.

TUNEL analysis was performed on paraffin section of $5 \mathrm{~mm}$ thickness of Bouin-fixed ventral prostatic lobes from c-Cbl deficient mice or wild-type mice. The slides were treated as already described [10].

LNCaP culture and treatment: the androgen-dependent human prostatic carcinoma cell line $\mathrm{LNCaP}$ was used obtained from generous gift of Pr. L. Morel [28] at the 60th passage. The cells were cultured as indicated by the manufacturer. For $\mathrm{H}_{2} \mathrm{O}_{2}$ or etoposide treatment, cells were cultured for $16 \mathrm{~h}$ or $24 \mathrm{~h}$ with indicated concentrations.

\section{RNA silencing and cDNA transfections}

The RNA silencing was done using Lipofectamine 2000 following the manufacturer's instructions (Invitrogen). The c-Cbl RNAi was generated by Eurogentec, whose sequence is: 5'GGGAAGGCUUCUAUUUGUU3'. The siRNA controls were purchased from Invitrogen: siRNA-A (sc-37007) and siRNA-B (sc44230). The Grb-2 siRNA was obtained from Santa-Cruz Biotechnology laboratories.

pcDNA3-120 cbl was very generously provided by Dr W.Y. Langdon. Transfections of c-cbl-deficient MEF were done using Lipofectamine 2000 following the manufacturer's instruction (Invitrogen).

\section{Human sample treatments}

Frozen tissue samples were obtained from six consenting patients (P1 to 6) following total prostate resection and used for western blotting. For immunohistochemistry experiments, slides of BPH and prostatic adenocarcinoma were fixed for $24 \mathrm{~h}$ (Bouin), dehydrated and embedded in paraffin. Sixteen prostatic adenocarcinomas were examined versus eight $\mathrm{BPH}$. Normal surrounding tissue served as controls.

Tissue microarrays were purchased from TMA US Biomax and were used to compare diverse cancer spots with normal ones. Spots of a minimum of six patients were analysed for a given pathology and seventeen organs considered.

\section{Automated immunohistochemistry analysis}

The IHC procedure was performed with a Ventana Benchmark XT autostainer using the manufacturer's procedure. After paraffin removal, the slides were submitted to antigen retrieval with Cell Conditioner for $30 \mathrm{~min}$ at $95^{\circ} \mathrm{C}$. Slides were incubated for $32 \mathrm{~min}$ at $37^{\circ} \mathrm{C}$ with specific primary antibodies. A Ventana-kit was applied including biotin/avidin/phosphatase system and the chromogen FastRed. Slides were counterstained with hematoxylin. Negative controls consisted in omitting the specific primary antibodies. Specimens were considered immuno-positive when $1 \%$ or more of the tissue had clear evidence of immuno-staining. The immuno-staining was evaluated by two independent observers.

\section{Image acquisition and manipulation}

The images were acquired using a microscope (Axioskop; Carl Zeiss MicroImaging, Inc.) with plan-Neofluar objective lenses (Carl Zeiss MicroImaging, Inc.) at $40 \times / \mathrm{NA} 0.75$. Observations were performed with a 3,200 K halogen light with a daylight blue filter using a digital imaging medium. DAB chromogen was used. The camera (Coolpix 990; Nikon) used the Nikon acquisition software. Manipulations were performed at room temperature. Image processing was performed with Adobe Photoshop. Only the whole images were processed with brightness, contrast, and color balance adjustments.

\section{Statistical analyses}

Data are expressed as the mean S.D. Three to seven animals from different litters were used. For statistical analysis of data generated in both in-vivo and in-vitro models, one-way ANOVA was performed to determine whether there were differences between all groups $(\mathrm{P}<0.05)$, and then the Bonferroni post-test was performed to determine the significance of the differences between the pair of groups. $\mathrm{P}<0.05$ was considered significant. The statistical tests were performed on Stat View software version 5.0 (SAS Institute Inc.).

\section{Results}

\section{c-Cbl down-regulates apoptosis in mouse ventral prostate through the apoptotic mitochondrial pathway}

In order to relate apoptosis directly to the expression of $\mathrm{c}-\mathrm{Cbl}$ in vivo, we investigated the apoptotic status in prostatic ventral (PV) cells of c-Cbl-deficient (KO) mice [24] compared with wild type (WT) mice (western blots were processed identically, and bands were compared only to bands from the same gel). We used prostate cells because of the androgen ability to affect the survival/apoptosis balance of ventral prostatic epithelial cells $[29,30]$. We first assessed the c-Cbl dependency on androgens through several means, clarified in supplementary information (Figures SI 1 and SI 2). All experiments clearly showed that c-Cbl expression is androgen-dependent in rat and mouse ventral prostate epithelial cells, decreasing with the progressive occurrence of apoptosis. We then addressed the role of $\mathrm{c}-\mathrm{Cbl}$ in this process.

The mitochondrial pro-apoptotic factors BimEL and Smac/ DIABLO were significantly increased in the ventral prostatic cells of c-Cbl-deficient mice (Figures 1A and B) compared to wild type mice. We also found the apoptotic factor Bak significantly elevated in deficient mice (Figures 1C). Conversely, the inhibitors of apoptosis c-IAP1 and XIAP were significantly lower in c-Cbl-deficient mice, when c-IAP2 was not affected (Figures 1D, E and F). Finally, the mitochondrial activated caspase-9, as well as procaspase-6, were found slightly and constantly elevated in c-Cbl-deficient mice (Figures $1 \mathrm{G}$ and $\mathrm{H}$ ), indicating the involvement of the mitochondrial apoptotic pathway. TUNEL experiments confirmed these data (Figures 1I), showing a slight but significant increase of the number of c-Cbl-deficient apoptotic epithelial cells. Flutamide treatment, at the doses used, did not change the increased apoptotic ratio when c-Cbl deficient mice and WT control mice were compared (Figures $1 \mathrm{H}$ and I). Therefore, we consider $\mathrm{c}-\mathrm{Cbl}$ as an average anti-apoptotic regulator in prostate epithelial cells that increases the physiological apoptotic threshold, with no specific interference with the anti-androgen apoptosisinducing pattern.

c-Cbl strongly protects primary mouse embryonic fibroblasts against oxidative stress 
A

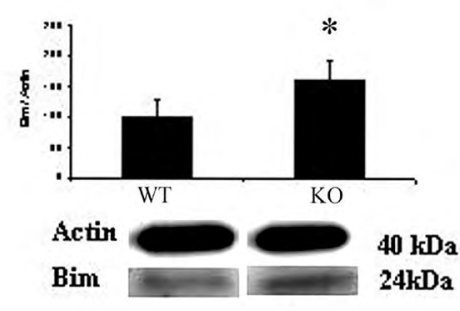

D
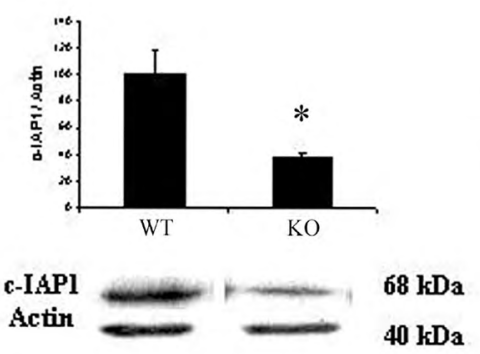

G

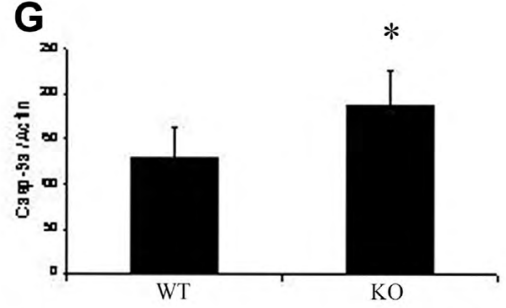

Activ
Casp-9 a $40 \mathrm{kDa}$

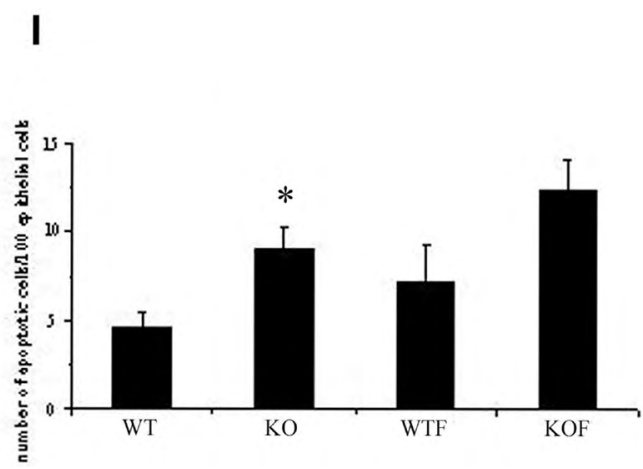

C

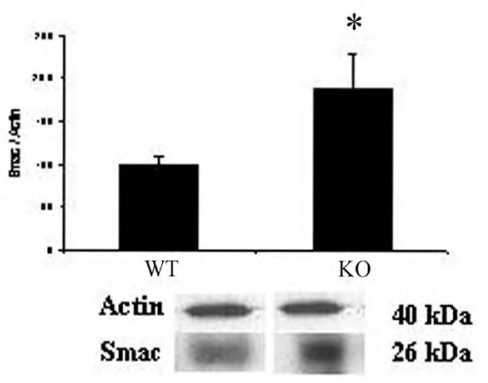

E
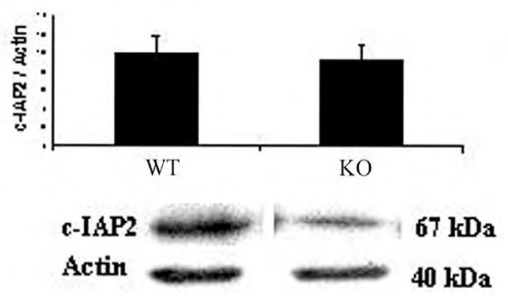

F

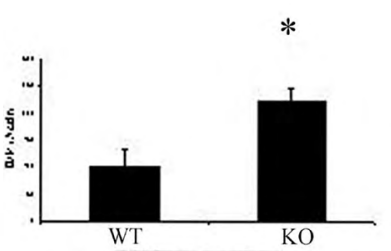

Activ

$40 \mathrm{kDa}$

Bak the $29 \mathrm{kDa}$

H

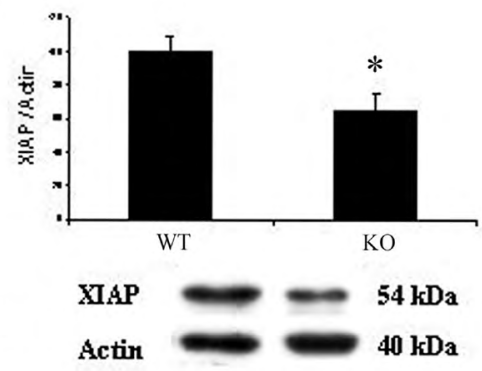

Actin

$40 \mathrm{kDa}$

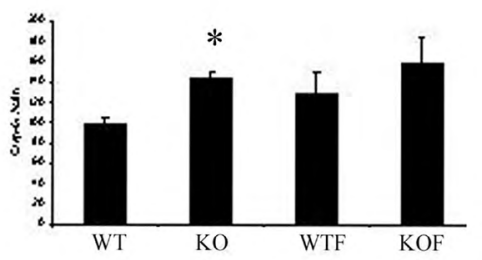

Actin $=0 \mathrm{kDa}$

Pro-Casp-6 $035 \mathrm{kDa}$

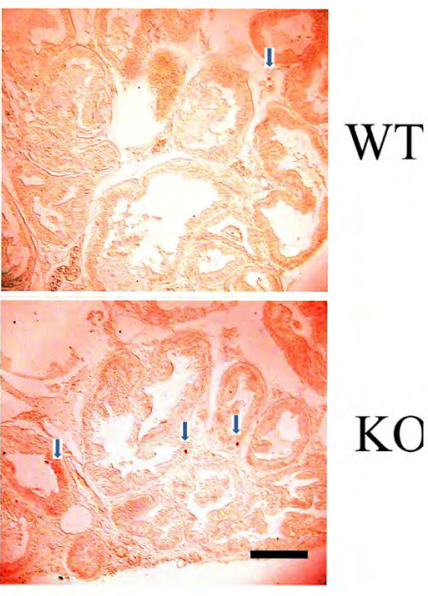

Figure 1: c-Cbl down-regulates the mitochondrial apoptosis pathway of mouse ventral prostate. One representative in vivo experiment of three independently conducted is reported. The number of mice used was at least $6(n=6)$. A , B and $\mathbf{C})$ BimEL expression is significantly higher in KO mice ( $p=0.048)$ as is Smac/DIABLO $(p=0.0183)$ and Bak $(p=0.042)$, compared to WT mice. $\mathbf{D}, \mathbf{E}$ and $\mathbf{F})$ The inhibitor of apoptosis c-IAP1 is significantly lower in KO VP ( $p=0.0201)$ as is XIAP $(p=$ $0.035)$ compared to WT mice, whereas c-IAP2 is not. G) Processed (activated) caspase- 9 was significantly higher in KO VP ( $p=0.046)$. H) Procaspase-6 expression level after three day of $10 \mathrm{mg} / \mathrm{kg} /$ day flutamide treatment (WTF versus KOF) is increased in KO mice $(p=0.0476)$ as it was with untreated mice $(\mathrm{WT}$ vs KO) $(p=$ 0.0487). The ratio WT/KO stayed the same. I) Number of apoptotic cells from TUNEL experiments counted from c-Cbl KO and WT mouse VP tissue sections. The number of apoptotic cells reported to 100 epithelial cells from flutamide treated animals is indicated. KO VP supports significantly more apoptotic cells than WT ( $p=$ $0.0014)$. The ratio WT/KO stayed the same. TUNEL positive cells on VP sections of WT and KO untreated animals are showed on the right. Magnification bar $=50 \mu \mathrm{m}$. 
In order to reveal better the anti-apoptotic potential of c-Cbl using appropriate controls, we evaluated the apoptotic level of ex vivo primary mouse embryonic fibroblasts (MEFs) from c-Cbl-deficient mice (KO) compared to the same c-Cbl ${ }^{+/+}$regular control strain mice (WT). As in vitro apoptotic inducers, we used the c-Jun kinase-dependent inducer hydrogen peroxide $\left(\mathrm{H}_{2} \mathrm{O}_{2}\right)$ and the $\mathrm{p} 53$ dependent inducer etoposide.

BimEL expression was up-regulated in KO-MEFs compared with WT (Figure 2A): we observed a spontaneous increased expression of the pro-apoptotic BH3-only protein in MEFs (Figure. 2A) as well as in c-Cbl-deficient mice (Figure 1A) in accordance with Akiyama completed by Wiggins et al. reports $[9,31]$, with Thien et al. $[11,12]$, and as we have reported occurring in mouse testis [10].

The expression level of XIAP and c-IAP1 were similar in $\mathrm{KO}$ and WT MEF untreated controls (Figures $2 \mathrm{~B}$ and $\mathrm{C}$ ), whereas they were spontaneously low in $\mathrm{c}$-Cbl deficient mice (Figure $1 \mathrm{D}$ and F). In contrast, the apoptotic activation by hydrogen peroxide or etoposide at the indicated concentrations initiated a significant decrease of the c-IAP1 and XIAP to about one third of the control level solely in KOMEFs, demonstrating the $\mathrm{c}-\mathrm{Cbl}$ sensitivity of these caspase-inhibitors (Figure 2B and C). The spontaneous caspase- 3 activation of these cells was almost undetectable in the untreated KO cells compared to WT and slightly higher in the etoposide treated $\mathrm{KO}$ cells (Figure 2D, two first panels on the top). However, a drastically increased expression of activated caspase- 3 is seen in $\mathrm{KO}$ cells stimulated by hydrogen peroxide: it is more than five times the expression of WT cells when compared to actin expression (Figure 2D). Experiments with c-Cbl reconstituted cells from $\mathrm{c}$-Cbl deficient mice compared to c-Cbl-deficient cells that were transfected with an empty vector gave very similar results, consistent with $\mathrm{c}$-Cbl being the only cause of the differences between the two cell-types (Figure 2D, two last panels).

A variety of doses and times of treatments led to a greater number of apoptotic KO-MEFs compared to WT (Figure 2E) after DAPI count, which were always significant upon hydrogen peroxide treatment These data validate the anti-apoptotic regulation exerted in vivo by c-Cbl, and confirmed its protective cellular effect against oxidative stress, at least in MEFs.

\section{c-Cbl is over-expressed in several human malignant tumours}

Tumour cells sustain a major resistance to apoptosis and we reported above that c-Cbl down-regulates cellular apoptosis. Therefore, it could promote cancer survival. We then explored the expression status of $\mathrm{c}$-Cbl in malignant pathologies. Western blots of prostate tumour tissues from six untreated patients compared to healthy surrounding tissue, show a strong $\mathrm{c}$ - $\mathrm{Cbl}$ cancer expression in all samples that ranged to 6 times normal expression (Figure $3 \mathrm{~A}$ ). In situ staining in tissue microarrays (TMA) assays confirmed this result (Figure $3 \mathrm{~B}$ ). We performed in situ staining in numerous TMA assays encompassing cancers from different origins (Figure $3 \mathrm{~B}$ to $\mathrm{J}$, right columns) compared to healthy corresponding tissues (left columns), revealing $\mathrm{c}-\mathrm{Cbl}$ over-expression in numerous cancers. Assay reading was double-blind. Eight of 16 studied non-prostate malignant tumours are positive for $\mathrm{c}-\mathrm{Cbl}$, as displayed on Figure 3, panels $\mathrm{C}$ to J: ovary serous papillary carcinoma $(\mathrm{C})$, uterus squamous cellular carcinoma (D), striated muscle rhabdomyosarcoma (E), astrocytoma (brain, F), lung squamous carcinoma $(\mathrm{G})$, colon and rectum adenocarcinoma $(\mathrm{H}$, $\mathrm{I})$, and diffuse large $\mathrm{B}$ cell lymphoma (J). The tumours considered not positive for $\mathrm{c}-\mathrm{Cbl}$ are reported in supplementary information (Figure

\section{SI 3) and in Table 1.}

We noticed that though rhabdomyosarcoma is strongly stained, liver carcinoma does not express c-Cbl significantly compared to healthy tissue (Figure SI 3A). This observation could be related to the key role that $\mathrm{c}-\mathrm{Cbl}$ plays in energy expenditure regulation in striated muscle but not in liver, as reported by Molero et al. [32,33]. Indeed, it was observed that insulin receptor levels were strongly increased only in the muscle of $\mathrm{c}-\mathrm{Cbl}^{-/-}$mice when compared to liver and we hypothesize c-Cbl over-expression in cancer affects cellular energy expenditure regulation.

We also observed a high c-Cbl expression in healthy tissues such as epidermis, stomach, and oesophagus (Figure SI 3B, D and E) that does not support a c-Cbl over-expression in the corresponding carcinomas, though it has been claimed that stomach adenocarcinoma was positive for c-Cbl [34]. It is also notable that c-Cbl alterations have been reported in lung cancers [35] as well as in myeloid malignancies [36-38].

Finally, we show that the staining intensity of $\mathrm{c}-\mathrm{Cbl}$ in prostate increases with the aggressiveness of the malignancy, as also found by Knight et al. [23]. Figure SI 4 A shows a prostatic benign hypertrophy whereas panels B to $\mathrm{F}$ represent prostatic adenocarcinoma of increasing grade. All these results strongly suggest that $\mathrm{c}-\mathrm{Cbl}$ has a positive effect over the growth of several cancers.

\section{c-Cbl up-regulation mostly associates with cellular oxidative stress}

We demonstrated that $\mathrm{c}$-Cbl protects cells against the oxidative stress that is often sustained by cancer cells [39], noting that c-Cbl is highly expressed in these malignant cells, as reported above. Therefore, we looked for a correlation between $\mathrm{c}-\mathrm{Cbl}$ and oxidative stress. We tested 11 cancers with the anti-apurinic/apyrimidic endonuclease APE1/REF1 (TMA staining), reflecting the oxidative stress undergone by the malignant cells [40]. We compare APE1 staining (right columns) to the control of the same tissue (left columns) (Figures 4).

\begin{tabular}{|l|c|c|c|c|}
\hline \multicolumn{3}{|c|}{ c-Cbl expression } & \multicolumn{2}{c|}{ APE1 expression } \\
\hline Tissue & NT & T & NT & T \\
\hline Prostate & w & h & w & h \\
\hline Breast & h & h & h & h \\
\hline Ovary & w & h & w & h \\
\hline Uterus & w & h & w & h \\
\hline Brain & w & h & w & h \\
\hline Muscles & w & h & w & h \\
\hline Lung & w & h & w & h \\
\hline Liver & h & h & w & h \\
\hline Kidney & h & h & h & w \\
\hline Bladder & h & h & w & h \\
\hline Pancreas & h & h & w & h \\
\hline Lymph nodes & w & h & nd & nd \\
\hline Colon & w & h & nd & nd \\
\hline Rectum & w & h & nd & nd \\
\hline Skin & h & h & nd & nd \\
\hline Oesophagus & h & h & nd & nd \\
\hline Stomach & h & h & nd & nd \\
\hline
\end{tabular}

Table 1: Summary of c-Cbl expression and corresponding APE1 expression in non-tumoral and tumoral human tissues. APE1 reflects the oxidative stress sustained by cells. All malignancies and corresponding tissues analyzed in this work were stained either by the anti-c-Cbl (left column) or by the anti-APE1 (right column). NT: Non Tumoral Tissue; T: Tumour Tissue; W: Weak Expression; $\mathbf{H}$ High Expression; Nd: Not Done. 


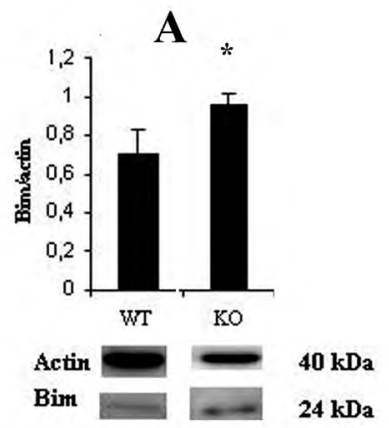

\section{BIM EL}

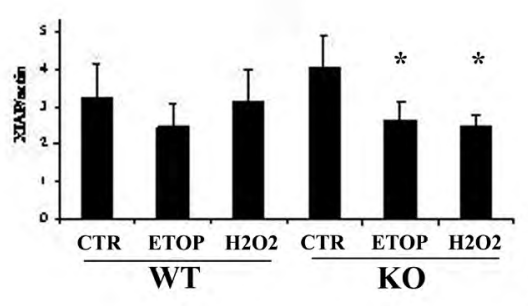

B

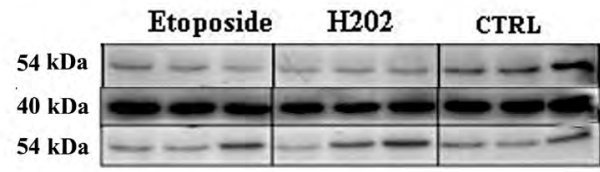

KO

Actin

$54 \mathrm{kD}$

WT

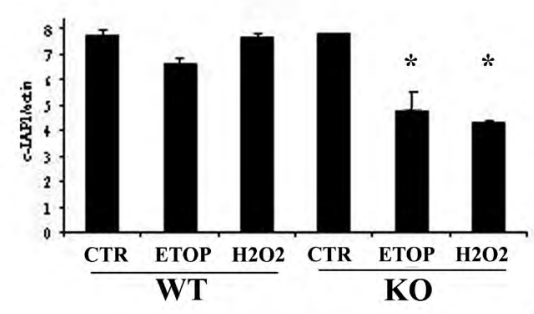

C

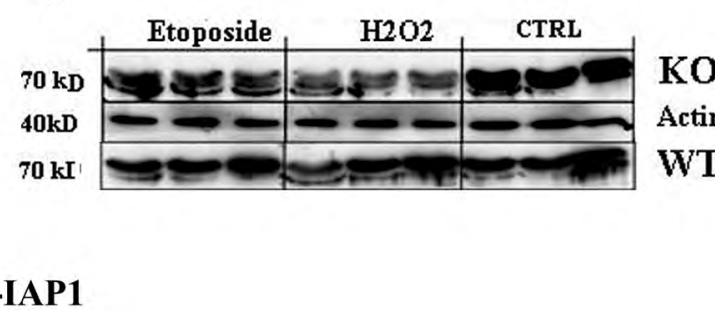

D
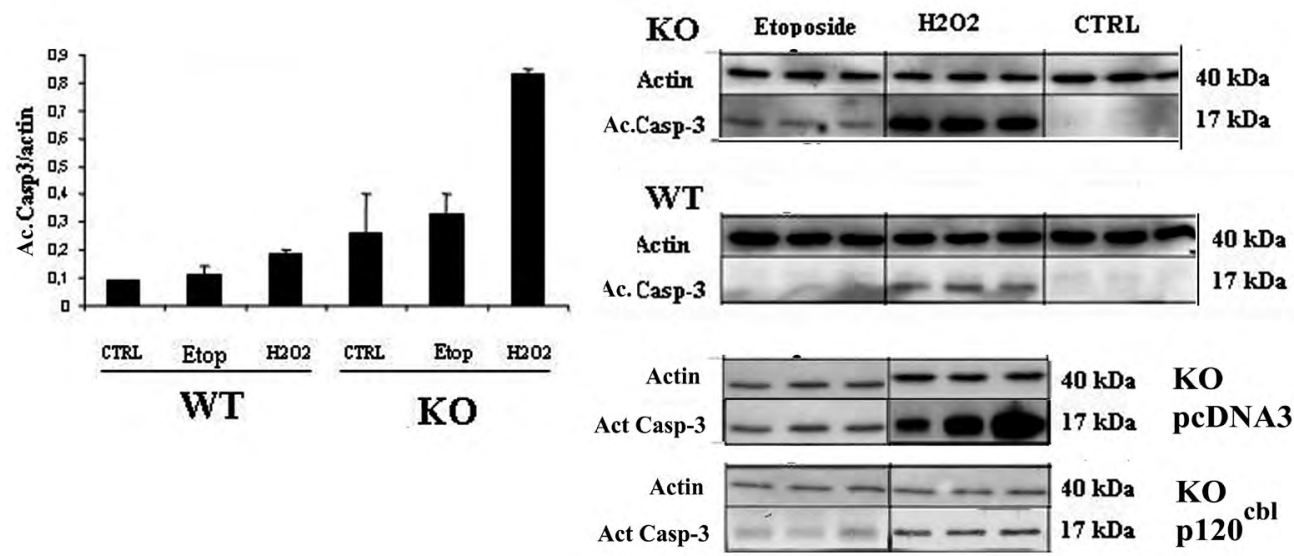


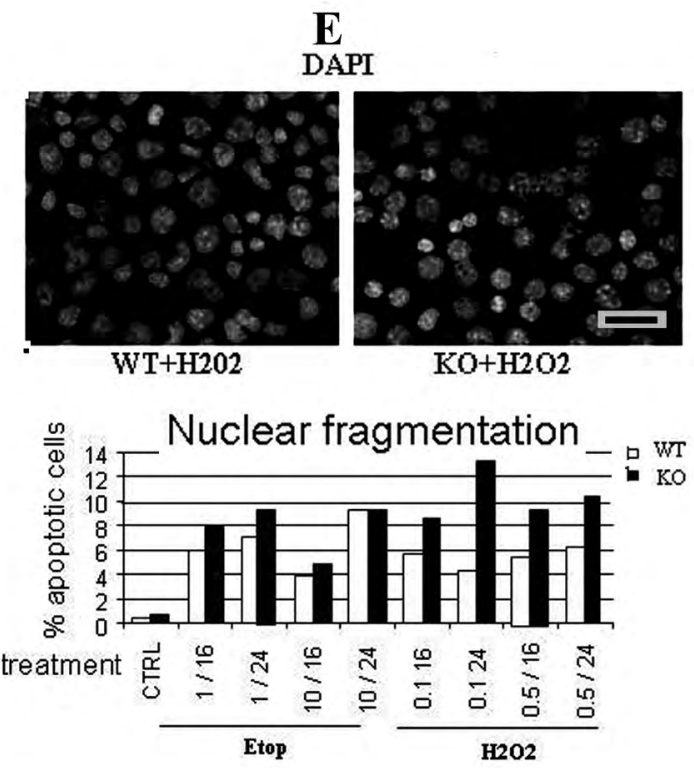

Figure 2: c-Cbl protects primary mouse embryonic fibroblasts (MEFs) predominantly against oxidative stress. One representative in vitro experiment is reported. The triplicate mean of protein expression level +/- s.e.m. is given. Etoposide were done at different concentrations. The optimal results were obtained with the indicated concentration. a: A) Bim EL is significantly higher in c-Cbl KO ( $p=0.032)$ compared to WT cells. B and C) The inhibitors of apoptosis XIAP and c-IAP1 expression in MEFs untreated $(\mathrm{CTRL})$ or treated by $0.1 \mathrm{mM}$ hydrogen peroxide $(\mathrm{H} 2 \mathrm{O} 2)$ for 24 hours were significantly lower than control in $\mathrm{KO}-\mathrm{MEFs}$ for $\mathrm{XIAP}\left(\mathrm{H}_{2} \mathrm{O}_{2} \mathrm{p}=0.0028\right.$; Etoposide $p=0,038)$ and for c-IAP1 $\left(\mathrm{H}_{2} \mathrm{O}_{2} \mathrm{p}=0.0016\right.$; Etoposide $\left.\mathrm{p}=0.023\right)$. b. D) Activated caspase-3 is strongly activated in KO-MEFs compared to WT ( $<<0.001$ ) only in the presence of $0.1 \mathrm{mM}$ of $\mathrm{H}_{2} \mathrm{O} 2$. Etoposide gave a much lower activation of activated caspase- 3 . The two right upper panels show the results of KO and WT MEFs, the two panels below, those of MEFs transfected with the vector alone (pcDNA3) and the c-Cbl expression vector. These different experiments gave very similar results. E) Nuclear fragmentation of the KO and WT MEFs revealed by DAPI staining experiments at diverse indicated concentrations ( $\mu \mathrm{M}$ for etoposide, mM for $\mathrm{H} 2 \mathrm{O} 2$ ) and after 16 or 24 hours of indicated treatment. The most effective concentrations for nuclear fragmentation were $1 \mu \mathrm{M}$ etoposide and $0.1 \mathrm{mM} \mathrm{H} 2 \mathrm{O} 2$ after 24 hours of treatment. On the upper panel, DAPI staining of MEF nuclei. Magnification bar $=20 \mu \mathrm{m}$.

We summarize the results on Table 1. Nine are positive for APE1. Among them, 6 are over-expressed for c-Cbl: prostate adenocarcinoma (A), ovary serous papilloma carcinoma (B), uterus squamous cellular carcinoma (C), rhabdomyosarcoma (D), astrocytoma (E) and lung squamous carcinoma $(G)$ as already shown in Figure 3B, C, D, E, F and $\mathrm{G}$, respectively. The three others: liver, bladder and pancreas carcinoma are found positive for APE1 (Figure $4 \mathrm{G}, \mathrm{J}$ and $\mathrm{K}$ ), whereas they are not for c-Cbl (Figures SI 3 A, C and G). However, these carcinomas are not as positive for APE1 as they are with the already described prostate, ovary carcinoma, and astrocytoma (Figures $4 \mathrm{~A}, \mathrm{~B}$ and $\mathrm{E}$ ), also displaying a very high c-Cbl over-expression (Figures $3 \mathrm{~B}, \mathrm{C}$ and F). Moreover, as said above, if the high $\mathrm{c}-\mathrm{Cbl}$ expression in cancer is related to the key role that c-Cbl plays in energy expenditure regulation $[32,33]$, it is not surprising that at least in the liver, c-Cbl is weakly expressed. Kidney and breast carcinoma were not considered positive for both stains (Figures SI $3 \mathrm{~F}$ and $\mathrm{H}$, respectively compared to Figures $4 \mathrm{I}$ and $\mathrm{H}$ ). Finally, these results are consistent with and association of strong oxidative stress and high c-Cbl expression in malignant cells (six c-Cbl positive among nine APE1 positive, no c-Cbl positive associated with APE1 negative).

\section{c-Cbl behaves as a protector of oxidative stress in LNCaP cell line}

In order to relate the apoptotic resistance against oxidative stress led by c-Cbl in MEFs to the effect of c-Cbl in human malignant cells, it was important to analyse c-Cbl's impact in a human cancer cell line. Our in vivo results suggested the human prostatic cancer cell line LNCaP.
We show that c-Cbl in LNCaP cell line cultured in the presence of very weak doses of hydrogen peroxide $(50 \mathrm{nM})$ or more substantial doses of etoposide $(30 \mu \mathrm{M})$ is slightly less expressed than control (CTL) (Figure 5A, first line). The anti-apoptotic factors analysed, Bcl2 and c-IAP2, are as expected, slightly less expressed upon the two apoptotic inducers in a dose-dependent manner (Figure $5 \mathrm{~A}$, second and third lines). The pro-apoptotic Bax protein expression increases compare with control (CTL) upon the two apoptotic inducers (Figure $5 \mathrm{~A}$, fourth line). Therefore we conclude that $\mathrm{c}$ - $\mathrm{Cbl}$ expression behaves as an anti-apoptotic factor. Another LNCaP experiment is clarified in supplementary information (Figure SI 5).

Experiments were then done with LNCaP subjected to c-Cbl RNA silencing (si-c-Cbl). The control panel (Figure 5B) shows the efficiency of the RNA silencing. We observe a lower expression of the anti-apoptotic modulator Bcl-2 that when LNCaP cells are subjected to si-c-Cbl RNA (si-c-Cbl) and $10 \mu \mathrm{M}$ hydrogen peroxide, compared to c-Cbl-expressing cells (si-Ctl) (Figure 5C, first line: column 4 versus 2 compare with column 3 versus 1), and to a lesser extent, c-IAP2 (Figure 5D: column 2 versus 3 compared to column 5 versus 6). Etoposide treatment $(30 \mu \mathrm{M})$ does not reveal a clear difference in Bcl-2 expression (Figure 5C, first line: column 5 versus 1 compare to column 6 versus 2) or in c-IAP2 (Figure 5D: column 1 versus 3 compared to column 4 versus 6). Conversely, the pro-apoptotic factor Bax is strongly increased in $\mathrm{LNCaP}$ cells undergoing $\mathrm{c}$-Cbl silencing with $10 \mu \mathrm{M}$ hydrogen peroxide (Figure 5C, third line: column 4 compared to column 3), to an extent equivalent to treatment with $30 \mu \mathrm{M}$ etoposide (Figure 5C, third line: column 5 compared to 6 ). This experiment clearly shows that when $\mathrm{c}-\mathrm{Cbl}$ expression is lowered, LNCaP cells under apoptotic stress 
Citation: Yakoub S, El-Chami N, Kaszas K, Malek M, El Sirkasi M, et al. (2014) The Proto-Oncoprotein c-Cbl Protects Cells against Oxidative Stress by Down-Regulating Apoptosis and is Highly Expressed in Several Cancers. J Cancer Sci Ther 6: 122-135. doi:10.4172/1948-5956.1000260
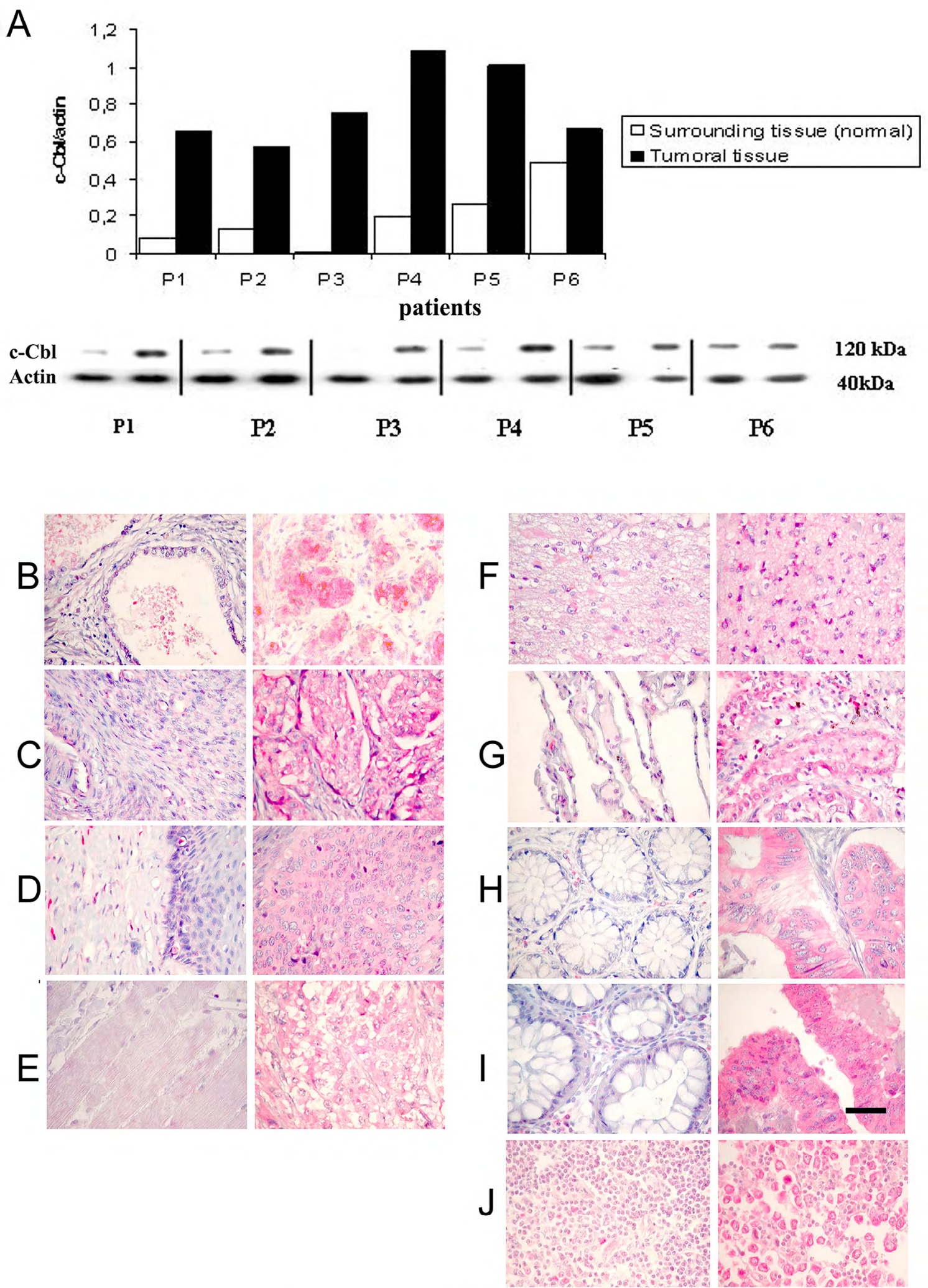

Figure 3: Human malignant tumours support a high c-Cbl expression. A) Western blotting of prostate cancer samples (black bar) compared to normal surrounding tissue (open bar) of six patients (P1 to P6). This experiment has been done 3 times (same patients). B to $\mathbf{J}$ ) tumor tissues (right pictures) and healthy correspondent tissues (left pictures) stained with the anti-c-Cbl. Tissue Microarrays (TMA) spots of at least 6 different patients showed equivalent results: B) prostate versus prostate adenocarcinoma; C) ovary versus serous papillary carcinoma; D) uterus versus squamous cellular carcinoma; $\mathbf{E}$ ) striated muscle versus rhabdomyosarcoma F) brain versus astrocytoma; G) lung versus squamous cellular carcinoma; H) colon versus colon adenocarcinoma; I) rectum versus rectum adenocarcinoma. J) lymph node versus lymphosarcoma. Magnification bar $=50 \mu \mathrm{m}$. 
Citation: Yakoub S, El-Chami N, Kaszas K, Malek M, El Sirkasi M, et al. (2014) The Proto-Oncoprotein c-Cbl Protects Cells against Oxidative Stress by Down-Regulating Apoptosis and is Highly Expressed in Several Cancers. J Cancer Sci Ther 6: 122-135. doi:10.4172/1948-5956.1000260

A

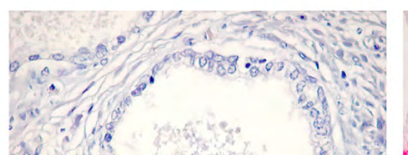

B
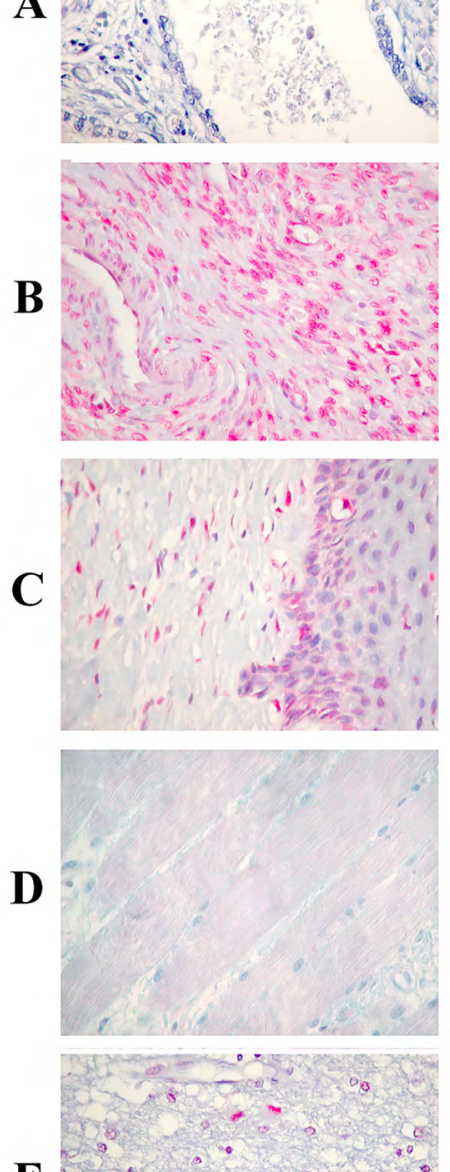

$\mathbf{E}$
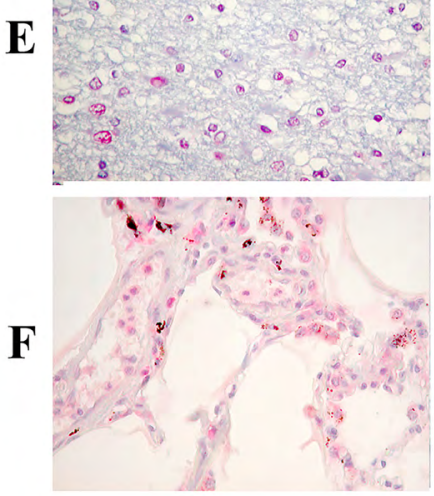
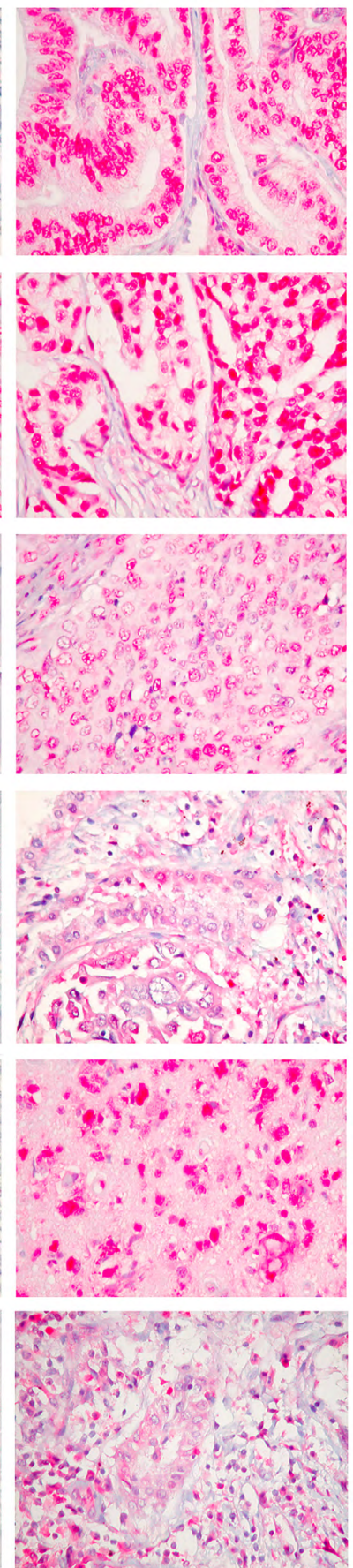

G
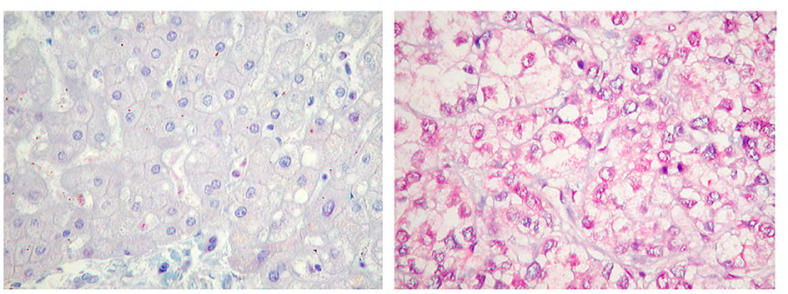

H
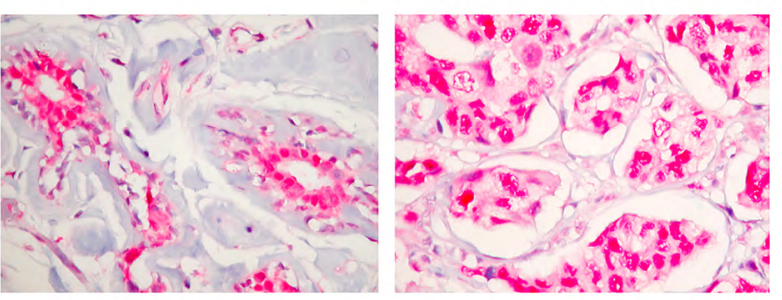

I
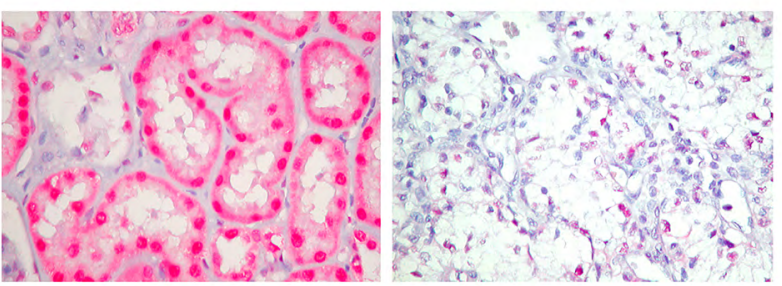

$\mathbf{J}$
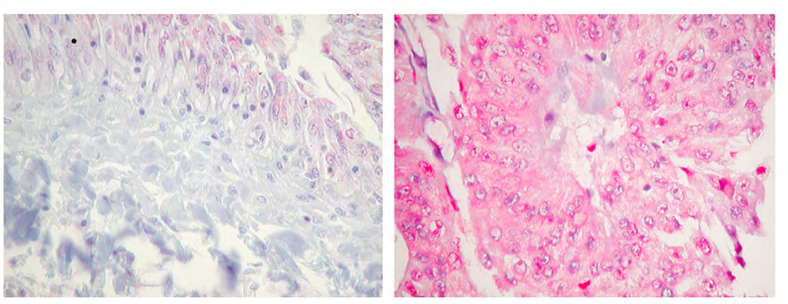

K
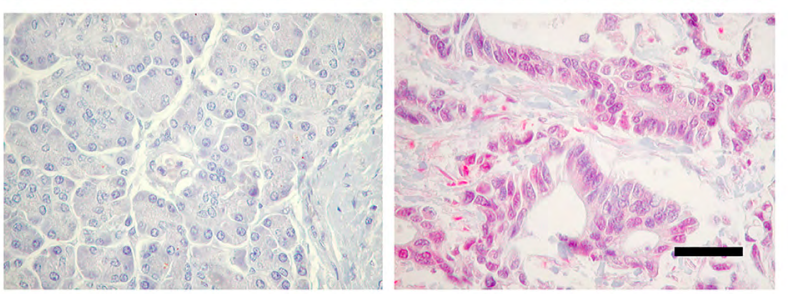

Figure 4: Malignant tissues support a high oxidative stress. Diverse normal tissues (left pictures) and tumour tissues of the same origin (right pictures) stained with anti-APE1. TMA spots of at least 6 different patients showed equivalent results. A): prostate versus prostate adenocarcinoma; B): ovary versus serous papillary carcinoma; C): uterus versus squamous cellular carcinoma; D): striated muscle versus rhabdomyosarcoma; E): brain versus astrocytoma; F): lung versus squamous cellular carcinoma; $\mathbf{G}$ ): liver versus hepato-cellular carcinoma; $\mathbf{H}$ ): breast versus infiltrated ductal carcinoma; I): kidney versus clear cell carcinoma; $\mathbf{J}$ ): bladder versus transitional cell carcinoma; K): pancreas versus pancreas adenocarcinoma. Magnification bar $=50 \mu \mathrm{m}$.

behave as do c-Cbl-deficient MEFs. This highlights the anti-apoptotic effect of c-Cbl in prostate cancer, which is particularly noticeable upon hydrogen peroxide treatment. Together, these results strongly suggest that $\mathrm{c}$-Cbl over-expression protects human malignant cells against apoptosis and particularly upon oxidative stress.
We also tested the level of endonuclease expression related to oxidative stress [40] in the LNCaP cell line subjected to transient silencing of $\mathrm{c}-\mathrm{Cbl}$ by monitoring the anti-APE1/REF1 signal (Figure 5E). We observed a slight decrease of the anti-APE1 signal in LNCaP submitted to c-Cbl RNA interference compared to the two control cell 

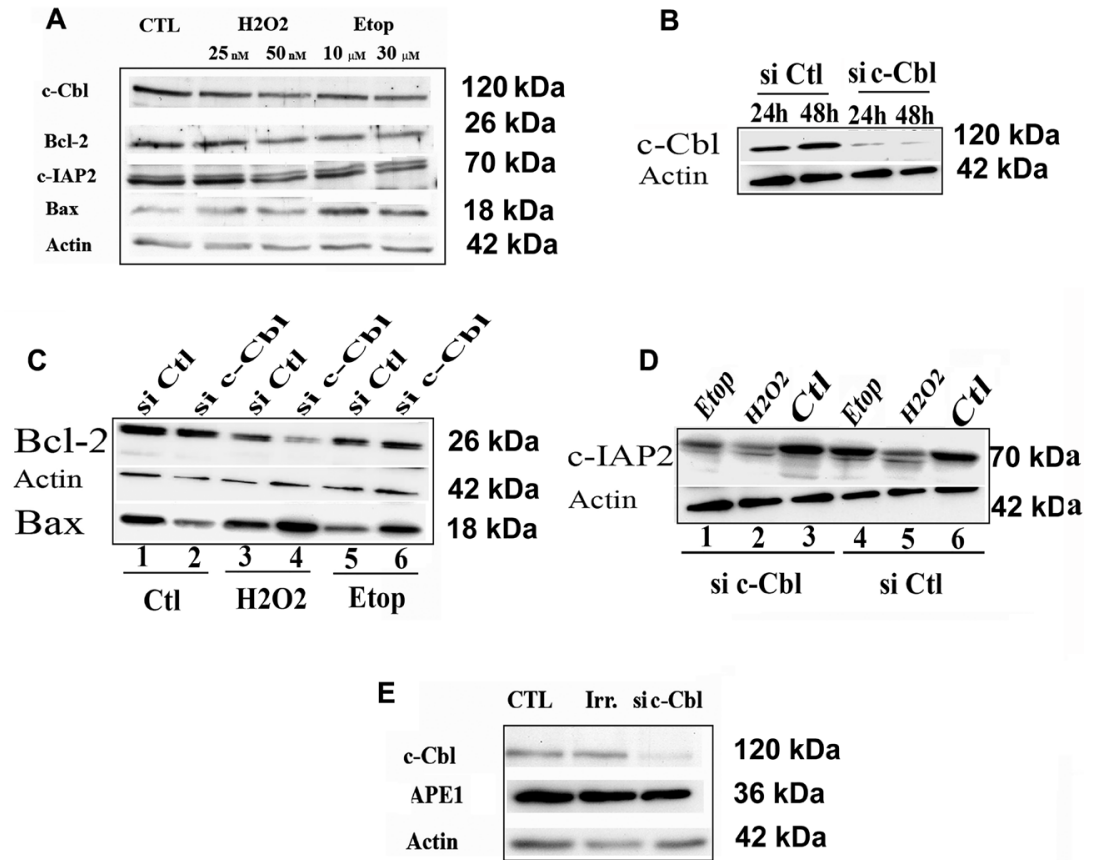

Figure 5: The proto-oncoprotein $\mathrm{c}-\mathrm{Cbl}$ is an anti-apoptotic modulator and protects human malignant cells against oxidative stress. One representative in vitro experiment realized with LNCaP cells is reported. A): The proto-oncoprotein c-Cbl expression decreased upon pro-apoptotic inductors (hydrogen peroxide or etoposide), behaving as the anti-apoptotic regulators Bcl-2 or c-IAP2, whereas the pro-apoptotic regulator Bax increased. B) Expression of c-Cbl subjected to c-Cbl siRNA (sic-Cbl) compared to Control siRNA (si Ctl) for 24 and 48h. C and D): c-Cbl down-regulates the mitochondrial apoptosis pathway of the human prostate cancer $\mathrm{LNCaP}$ cell line. C): $48 \mathrm{~h}$ of c-Cbl interference led to a strong Bcl-2 down-regulation (column 4) compared to c-Cbl-expressing cells (column 3 ) in the presence of $10 \mu \mathrm{g} / \mathrm{mL}$ of hydrogen peroxide $\left(\mathrm{H}_{2} \mathrm{O}_{2}\right)$. Etoposide at the dose of $30 \mu \mathrm{g} / \mathrm{mL}$ does not have the same effect (column 6 versus 5 ). Bax is highly expressed in the same conditions (column 4 versus 3 with $\mathrm{H}_{2} \mathrm{O}_{2}$, and column 6 versus 5 with etoposide). D): $10 \mu \mathrm{g} / \mathrm{mL} \mathrm{H}_{2} \mathrm{O}_{2}$ and $30 \mu \mathrm{g}$ etoposide led to a down-expression of c-IAP2 (column 2 and 1 versus column 3) more pronounced than in LNCaP control cells (column 5 and 4 versus column 6 ). E): 48H c-Cbl interference of LNCaP cell line decreases the endonuclease APE1 that reflects oxidative stress: LNCaP knocked-down for c-Cbl showed a slight decrease of APE1 compared to an irrelevant siRNA (irr.) or to medium control (CTL).

lines, suggesting that $\mathrm{c}-\mathrm{Cbl}$ could partly participate to the oxidative stress progress. This result correlates to the result that the presence of weak doses of hydrogen peroxides does not increase $\mathrm{LNCaP}$ c-Cbl expression as a negative feed-back regulation (Figure 5A). Thus, we can make the assumption that $\mathrm{c}-\mathrm{Cbl}$ participating in generating oxidative stress also allows cells to be protected against this stress, just as it is observed in malignant cells.

\section{c-Cbl down-regulates the ASK1-p38MAPK stress pathway activation}

In order to find a molecular mechanism leading c-Cbl to downregulate apoptosis in cancer cells, we explored the expression or activation (phosphorylation) of major kinases of the MAP kinase pathways (schematic view, Figure 6A) known to lead to apoptosis upon oxidative stress [41]. We found that MLK3 of the MAP3K family is expressed approximately two-fold more in untreated LNCaP cell line undergoing c-Cbl silencing than in control cells (Figure 6B, column 2 compare with 1 ). ASK1 of the same family is expressed five times more in c-Cbl-KO cells than in control cells (Figure 6C, column 2 compare with 1). The p38MAPK, which regulates apoptosis and stress responses, does not change its expression (Figure 6D), whereas we observe a dramatic over-phosphorylation of p38MAPK (Thr180/ Tyr182) in c-Cbl deficient cells (Figure 6E, column 2 compare with 1), clearly showing an over-activation of the MLK3/ASK1-p38MAPK regulation pathway and allowing apoptotic activation in untreated c-Cbl deficient cells.
Finally, we also observe that knocking down c-Cbl does not seem to have a clear effect on p38 expression when treated with $25 \mu \mathrm{M}$ hydrogen peroxide (Figure $6 \mathrm{~F}, \mathrm{H}_{2} \mathrm{O}_{2}$ treatment, column 2 compare with 1). On the contrary, $A R N$ interference with the molecular adaptor Grb2 (Grb2 siRNA), which allows c-Cbl translocation to the membrane upon TKR activation [1-5], clearly diminishes p38 expression (Figure $6 \mathrm{~F}$, non-treated $-\mathrm{NT}$, column 3 compare with 1). This result shows that Grb2 participates in the apoptotic regulation at least at the level of p38 expression, contrary to $\mathrm{c}-\mathrm{Cbl}$, which only down regulates p38 phosphorylation. The double knock-down (c-Cbl siRNA and Grb-2 siRNA) up-regulated p38 expression compared to the Grb-2 knockdown cells (Figure 6F, NT, column 4 compare with 3 ), and shows a slight subtractive effect of c-Cbl and Grb-2 over p38 expression. This result highlights the possibly unrelated effect of c-Cbl and Grb2 on p38 expression and growth factor receptor internalisation and regulation. The c-Cbl and Grb-2 RNA interference, single or coupled, were efficient in these experiments as shown in Figure 6G.

\section{Discussion}

This work has focused on the role of the proto-oncoprotein c-Cbl in cellular apoptosis in human cancers. We report c-Cbl overexpression in different human carcinomas (ovary, uterus, brain, lung, colon, rectum) and rhabdomyosarcoma (Figure 3), and confirm it in human prostatic carcinoma, demonstrating a correlation between c-Cbl over-expression and cancer aggressiveness (Figure SI 4) as previously reported by Knight et al. [23]. We also relate the intensity of 
A

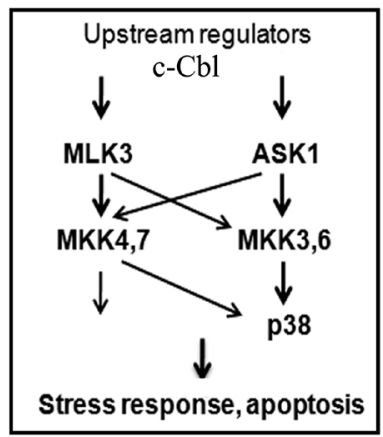

B

C

D

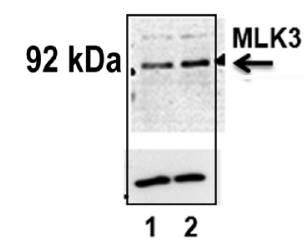

$150 \mathrm{kDa}$

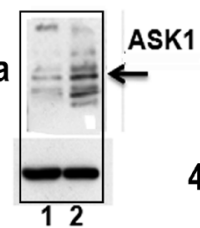

$42 \mathrm{kDa}$

F

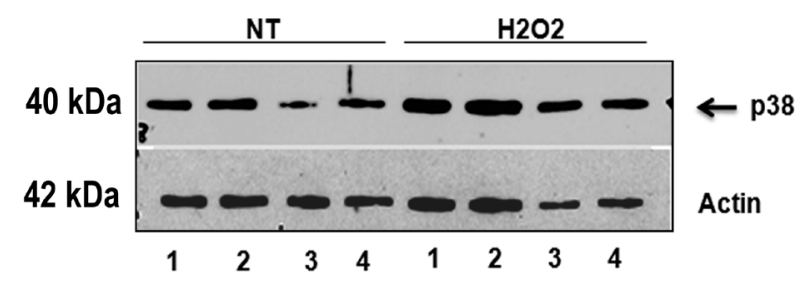

p38

$120 \mathrm{kDa}$

$24 \mathrm{kDa}$

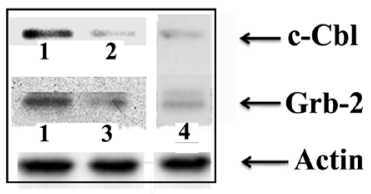

\section{1: si RNA Control \\ 2: si RNA Cbl \\ 3: si RNA Grb2 \\ 4: si RNA Cbl \& Grb2}

Figure 6: c-Cbl down-regulates the MLK3-ASK1-p38MAPK stress pathway leading to apoptosis. The c-Cbl associated p38 expression appears not to depend on the molecular adaptor Grb-2.

A) Overview of p38MAPK stress signalling pathway summarized from Matsuzawa and Ichijo [33] B to E) the expression of the kinases MLK3, ASK1, p38MAPK and phospho-p38MAPK have been compared in LNCaP cell line between control cells (siRNA control, column 1) and cells subjected to c-CbI RNA interference (column 2). F): expression of p38MAPK in LNCaP cell line treated 6 hours by $25 \mu \mathrm{M}$ hydrogen peroxide $\left(\mathrm{H}_{2} \mathrm{O}_{2}\right)$ or untreated (NT), as indicated. Column 1: siRNA control cells, column 2: c-Cbl siRNA cells, column 3: Grb-2 siRNA cells, column 4: c-Cbl and Grb-2 siRNA cells. G): effects of c-Cbl RNA interference (\#2), Grb-2 RNA interference (\#3) and c-Cbl plus Grb-2 RNA interference (\#4) compared to control (siRNA control, \#1), respectively on c-Cbl and Grb-2 expressions in LNCaP cell line.

c-Cbl staining (Figure 3 and Table 1) and the oxidative stress (Figure 4) supported by cancer cells. These observations suggest that c-Cbl expression is linked to the modulation of the ROS and to the survival of the cancer cells.

Aggressive tumors are reported to be more subject to oxidative stress [39], consistent with the correlation we report between oxidative stress, intensity of c-Cbl expression, and advanced stage of cancer development. The importance of $\mathrm{c}-\mathrm{Cbl}$ in tumorigenesis would benefit from assessment of larger numbers of diverse tumors (Table 1).

It has been reported that ROS leads to activation of diverse protein tyrosine-kinases $[42,43]$. Oxidative stress has been found responsible for dysfunction of $\mathrm{c}-\mathrm{Cbl}$ in down-regulating EGFR phosphorylation
[44]. We can then hypothesize that this dysfunction increases c-Cbl expression by positive feedback. However, LNCaP experiments gave opposite results, showing that upon hydrogen peroxide treatment, c-Cbl expression decreased, following the same expression pattern as the anti-apoptotic factors tested (Bcl-2, c-IAP2, Figure 5A). We also found that the c-Cbl knock-down decreases endonuclease APE1/ $\mathrm{REF} 1$, reflecting a decrease of oxidative stress intensity (Figure $5 \mathrm{E}$ ). Molero et al. [32,33] showed highly altered energy expenditure and strong increase activity of the AMP-activated protein kinase (AMPK) in the muscle of c-Cbl-deficient mice. They also reported that the uncoupling protein-3 (UCP3) was increased 1.9-fold in muscle in c-Cbl-deficient mice compared to controls. The uncoupling proteins are considered protectors of free radical oxygen species by decreasing 
the mitochondrial production of reactive oxygen species [45]. Thus, the data of Molero et al. completely accord to the c-Cbl negative feedback we find between c-Cbl expression and cellular oxidative stress as reflected by the monitoring of the anti-APE1/REF1 signal (Figure 5D) or the c-Cbl expression upon gradually $\mathrm{H}_{2} \mathrm{O}_{2}$ concentrations (Figure 5A). Therefore, we suggest that ROS production in cancer is substantially affected by alteration of c-Cbl expression, which could be itself a result of the peculiar pathway of energy consumption in malignant cells (Warburg effect) $[46,47]$ associated with its protective effect we report on these cells.

Resistance to apoptosis is the hallmark of the majority of cancers $[21,22,48,49]$. The c-Cbl regulation of apoptosis [8-22,50,51], highlights its role in cancer. Our study shows that $\mathrm{c}-\mathrm{Cbl}$ increases the apoptotic threshold in epithelial cells of mouse ventral prostate (VP). The MEF and $\mathrm{LNCaP}$ studies demonstrate that the absence of $\mathrm{c}-\mathrm{Cbl}$ renders the cells much more susceptible to apoptosis when subjected to oxidative stress, but less so upon other means of inducing apoptosis (etoposide in in vitro, flutamide in in vivo). Therefore, this work strongly suggests that the intense expression of $\mathrm{c}$-Cbl together with the high oxidative stress found in several types of cancer confers resistance to apoptosis in malignant cells.

Our results with inhibitors of apoptosis (XIAP and c-IAP1) indicate that $\mathrm{c}-\mathrm{Cbl}$ has anti-apoptotic potential (Figure 1D and F; Figure 2B and C), and increases the apoptotic threshold in vivo and in MEFs. The well-documented, increased expression of IAPs in cancer, particularly in high-grade prostate tumours, could be a consequence of the high c-Cbl expression we find in some cancers. Therefore, this increased expression of IAPs could be sufficient to alter caspase activities and protect malignant cells $[48,49]$

Conversely, we report (Figure 1A and Figure 2A) a spontaneous increased expression of the pro-apoptotic BH3-only protein BimEL (in

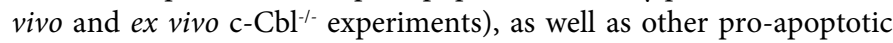
factors (Bak, Smac/DIABLO and the mitochondrial activated caspase 9). Thien et al. $[11,12]$ showed that a $\mathrm{c}-\mathrm{Cbl}$ mutant (c-CblA mice) that had lost its ubiquitine-ligase capability was highly pro-apoptotic and led to a markedly elevated activation of the pro-apoptotique factor BimEL. Thien et al.'s results support a key role of c-Cbl ubiquitineligase function in BimEL up-regulation and possibly in the antiapoptotic potential of $\mathrm{c}-\mathrm{Cbl}$ reported here.

The observation of strong caspase- 6 activity combined with the higher apoptotic cell number in the presence of hydrogen peroxide clearly demonstrates anti-apoptotic regulation by $\mathrm{c}$-Cbl in MEFs (Figure 2D). The LNCaP cell line experiments gave similar results (Figure 5A). In particular, hydrogen peroxide seems to be more effective in LNCaP cell lines than etoposide with the doses used and allows us to enlarge our MEF conclusions (c-Cbl mainly protects cells again oxidative stress) to the human cancer cell line.

These results seem a paradox: in our hands c-Cbl causes downregulation of apoptosis, while $\mathrm{c}-\mathrm{Cbl}$ is commonly considered as a downregulator of growth factor receptor, which means an anti-survival factor. Indeed, c-Cbl is reported to increase survival [18,19,52]. Edwin and Patel [18] showed that $\mathrm{c}-\mathrm{Cbl}$ reduces the anti-apoptotic activity of serum when the c-Cbl negative regulator Sprouty 2 was silenced. Bonaccorci et al. [52] reported that AR affects the clathrin-mediated endocytosis pathway of EGF-R via c-Cbl, which could explain the lower invasive phenotype observed in AR-positive cell lines and the anti-survival effect of c-Cbl. Yan et al. [19] reported that c-Cbl is involved in tamoxifen-induced apoptosis of MCF-7 cell line by downregulating the survival signals (c-Src, ERK and AKT) probably linked to TKR activation. In contrast, Lo et al. [53] showed that the ectopic over-expression of c-Cbl in non-small cell lung cancer (NSCLC) cell lines increases tumour growth and cell migration. Ito et al. [54] report that c-Cbl when linked to EGF Receptor is associated with gastric tumor progression. Interestingly, Sproul et al. [13] reported that c-Cbl interacts with the MLK-JNK pathway regulating negatively neuronal cell death, and Kim et al. [16] showed that the Src/CIN85-c-Cbl complex mediates a biphasic regulation of the pro-apoptotic TRAIL receptor through a MEKK4/p38/Hsp27/Akt pathway. These results re-enforce our own data in vivo and in vitro. Kim et al. also report that $\mathrm{c}-\mathrm{Cbl}$ knock-down sensitizes the apoptotic effect of TRAIL receptors [15]. These reports and ours clearly suggest that $\mathrm{c}-\mathrm{Cbl}$ protects cells against apoptosis through mitogen-activated protein (MAP) kinase pathways. We observe that c-Cbl has an anti-apoptotic potential that increases the apoptotic threshold as shown in our prostate cell experiments in vivo. It is likely that in many systems, c-Cbl's down-regulation of growth factors masks this anti-apoptotic aspect. However, in the presence of hydrogen peroxide, the anti-apoptotic potential of c-Cbl manifests and protects malignant cells against high oxidative stress (i.e. advanced stage of cancer), probably as we report here at least through inhibition of the p38MAPK stress pathway.

Indeed, we show that c-Cbl spontaneously down-regulates the expression level of several stress-activated protein kinase (SAPKs) of the MAPK pathways (Figure 6A to D). We also show that $\mathrm{c}-\mathrm{Cbl}$ negatively and strongly decreases activation (phosphorylation) of the p38MAPK (Figure 6E). Indeed, p38 is well-known to be regulated by environmental stress, as such hydrogen peroxide or pro-inflammatory cytokines (IL1 $\beta, T N F \alpha$ ), and to be a strong pro-apoptotic factor following oxidative injury [41]. Therefore, $\mathrm{c}$-Cbl has an obvious effect on down-stream signalling. We postulate that such a regulation could be linked to the TKR activation (EGF-R, PDGF-R) that has been shown to undergo atypical phosphorylation/dephosphorylation in response to oxidative insult [44], de-routing c-Cbl activation and releasing its anti-apoptotic potential. Our experiments suggest c-Cbl and Grb-2 have a different effect on p38 expression level and that their effects are subtractive. We speculate that Grb-2 sequesters c-Cbl and masks its anti-apoptotic effect. The paradox between survival effects of c-Cbl and its anti-apoptotic potential would then lie in the balance between the degree of c-Cbl TKR down-regulation (anti-survival) and the intensity of c-Cbl apoptotic inhibition (survival). The cellular redox level could play a determining role in this balance, oxidative stress favouring c-Cbl-linked apoptotic resistance.

Another interesting question emerges with the increased intensity of cellular apoptosis specific to hydrogen peroxide treatment of c-Cbl deficient cell cultures compared to the other apoptotic inductors as etoposide (MEFs) or flutamide (mouse prostate). As reported above $[13,16]$, different specific pathways have been found explaining the $\mathrm{c}-\mathrm{Cbl}$ apoptotic regulator role. It is then very possible that $\mathrm{c}-\mathrm{Cbl}$ has different targets and in our hands the most effective one appeared to be the MLK3/ASK1-p38MAPK stress pathway, involving the redox control of cell fate by MAP kinase.

The testosterone dependency of c-Cbl expression that we report (see Supplementary Information) links c-Cbl to the survival process led by AR activation. It clearly increases the apoptotic threshold of androgendependent cells, but it does not specifically protect these cells during testosterone withdrawal: in the in vivo model, the cellular apoptotic 
$\mathrm{WT} / \mathrm{KO}$ ratio did not change upon flutamide treatment (Figure 1I). In LNCaP cells, $\mathrm{c}$-Cbl expression decreases upon high testosterone concentration and is tightly associated to pro-apoptotic behaviour (Figure SI 5), reflecting the c-Cbl expression pattern observed in vivo (Figure SI 1 and 2). These points are clarified in the Supplementary Information. It is not clear if the strong decrease of the cell number at high testosterone doses is due to apoptotic onset [28] or to G1 arrest, as reported by Kokontis et al. [55]. G1 arrest could permit cells to escape apoptosis. This aspect could also be related to a large TKR degradation with c-Cbl expression decrease associated to abnormal stimulation of the androgen receptor as described by Bonnacorsi et al. [52].

In summary, c-Cbl down-regulates TKR, therefore it can be seen as an anti-survival factor, and it could also independently control downstream signalling pathway inhibition, such as SAPKs, and thus be seen as a pro-survival factor that is tightly dependent on the redox level. Consequently, it could control the survival/death balance as a complete integrated modulator. Its pro-survival (anti-apoptotic) aspect could be dependent on its ubiquitine-ligase capability, as suggested by the reports of Langdon et al. [11,12], without being directly dependent on the TKR down-regulation by itself. Therefore, we can assume that c-Cbl plays a role in down-regulating SAPKs, possibly through its ubiquitinylation ability $[11,12]$, allowing survival of over-expressing c-Cbl malignant cells by rendering it tolerant to oxidative compounds. Additionally, c-Cbl could also promote the renewal of these compounds as suggested by our data (Figure 5E) and the reports of Molero et al. [32,33], thereby increasing mutation in cancer cells.

\section{Acknowledgments}

We thank Dr Hua Gu and Dr Naramura (NIH, NIAID) for generously providing c-Cbl- deficient mice and Dr Decaussin-Petrucci (Department of Cytopathology of Lyon-Sud Hospital) for generously providing human prostate slides and for participating to the in situ staining interpretation. We also thank Dr W.Y. Langdon (University of Western Australia, Perth, Australia) for generously providing $\mathrm{c}-\mathrm{Cb}$ c-DNA. We thank Pr L. Morel (UMR 6547, Blaise Pascal University, Aubière France) and Dr R. Grataroli (Lyon-Sud Faculty, Oullins, France) for generously providing $\mathrm{LNCaP}$ cell lines. We thank Dr M. Benahmed and Dr C. Mauduit for opening their laboratory to our in vivo experimentations, for their invaluable advices and for generously furnishing the human prostate samples for western-blotting We are very grateful to $\mathrm{Dr} \mathrm{S}$. Chater for her technical assistance in rat castration experiments and to Lisa Borghini and Pauline Mourier for technical assistance in LNCaP experiments. We also are very grateful to Dr. David Vindrieux (CLB, Lyon, France) for great advices and technical assistance in $\mathrm{LNCaP}$ experiments.

\section{Author contributions and funding}

SY and NEC performed in vivo experiments. SY performed LNCaP experiments. KK prepared and analysed mouse embryonic fibroblasts. MM was of great experimental help in the LNCaP experiments. MES participated to the in vivo $\mathrm{C}-\mathrm{Cbl}$ androgen-dependency experiments. ET supervised the in situ staining, and crucially contributed to interpret results. SM, CAS and EB allowed this research to be pursued in generously opening their laboratories, giving invaluable advices and kindly correcting the manuscript. DCLR designed and supervised experiments, interpreted results and wrote the manuscript.

This work was supported by the Institut National de la Santé et de la Recherche Médicale (INSERM U407), by the "Ligue Régionale de la Loire Contre le Cancer" (2008-2012, subsidy to D.R.), by the American University of Beirut (2010-2012, subsidy to E.B.) and by the CEDRE (2010-2012, reference 10SF26/L28, subsidy to E.B. and D.R.).

SY was granted first by the Hospices Civils de Lyon (research assistant), by the "Société d'Andrologie de Langue Française" (SALF), then by the "Fondation pour la Recherche Médicale" (FRM, FDT 20070910376); NEC was granted first by "Organon Laboratory" (FARO grant), then by the "Fondation pour la Recherche Médicale" (FRM, FDT 20061209043) and finally by the American University of Beirut (2010-2011); KK received an Allocation for research (University Claude Bernard Lyon-1, contract 6552-2002 UCBL) then a grant from the "Ligue Nationale Contre le Cancer" (Ref JG/VP-5442 LNCC); MES received an Allocation for research from INSERMU407; MM was granted by the French Research and Technology Ministry (MRT).

\section{References}

1. Schmidt MH, Dikic I (2005) The Cbl interactome and its functions. Nat Rev Mol Cell Biol 6: 907-918.

2. Thien CB, Langdon WY (2005) c-Cbl and Cbl-b ubiquitin ligases: substrate diversity and the negative regulation of signalling responses. Biochem $\mathrm{J} 391$ 153-166.

3. Thien CB, Langdon WY (2005) Negative regulation of PTK signalling by Cbl proteins. Growth Factors 23: 161-167.

4. Jiang X, Huang F, Marusyk A, Sorkin A (2003) Grb2 regulates internalization of EGF receptors through clathrin-coated pits. Mol Biol Cell 14: 858-870.

5. Stern KA, Place TL, Lill NL (2008) EGF and amphiregulin differentially regulate $\mathrm{Cbl}$ recruitment to endosomes and EGF receptor fate. Biochem J 410: 585-594.

6. Donovan JA, Wange RL, Langdon WY, Samelson LE (1994) The protein product of the c-cbl protooncogene is the $120-\mathrm{kDa}$ tyrosine-phosphorylated protein in Jurkat cells activated via the $\mathrm{T}$ cell antigen receptor. J Biol Chem 269: 22921-22924.

7. Rivero-Lezcano OM1, Sameshima JH, Marcilla A, Robbins KC (1994) Physica association between $\mathrm{Src}$ homology 3 elements and the protein product of the c-cbl proto-oncogene. J Biol Chem 269: 17363-17366.

8. Hamilton E, Miller KM, Helm KM, Langdon WY, Anderson SM (2001) Suppression of apoptosis induced by growth factor withdrawal by an oncogenic form of c-Cbl. J Biol Chem 276: 9028-9037.

9. Akiyama T, Bouillet P, Miyazaki T, Kadono Y, Chikuda H, et al. (2003) Regulation of osteoclast apoptosis by ubiquitylation of proapoptotic $\mathrm{BH} 3-$ only Bcl-2 family member Bim. EMBO J 22: 6653-6664.

10. El Chami N, Ikhlef F, Kaszas K, Yakoub S, Tabone E, et al. (2005) Androgendependent apoptosis in male germ cells is regulated through the protooncoprotein Cbl. J Cell Biol 171: 651-661.

11. Thien CB, Blystad FD, Zhan Y, Lew AM, Voigt V, et al. (2005) Loss of C-Cb RING finger function results in high-intensity TCR signaling and thymic deletion. EMBO J 24: 3807-3819.

12. Thien CB, Dagger SA, Steer JH, Koentgen F, Jansen ES, et al. (2010) C-Cb promotes $T$ cell receptor-induced thymocyte apoptosis by activating the phosphatidylinositol 3-kinase/Akt pathway. J Biol Chem 285: 10969-10981.

13. Sproul AA, Xu Z, Wilhelm M, Gire S, Greene LA (2009) Cbl negatively regulates JNK activation and cell death. Cell Res 19: 950-961.

14. Xu L, Qu X, Zhang Y, Hu X, Yang X, et al. (2009) Oxaliplatin enhances TRAILinduced apoptosis in gastric cancer cells by CBL-regulated death receptor redistribution in lipid rafts. FEBS Lett 583: 943-948.

15. Kim SY, Kim JH, Song JJ (2013) c-Cbl shRNA-expressing adenovirus sensitizes TRAIL-induced apoptosis in prostate cancer DU-145 through increases of DR4/5. Cancer Gene Ther 20: 82-87.

16. Kim J, Kang D, Sun BK, Kim JH, Song JJ (2013) TRAIL/MEKK4/p38/HSP27/ Akt survival network is biphasically modulated by the Src/CIN85/c-Cbl complex. Cell Signal 25: 372-379.

17. Sévère N, Dieudonné FX, Marie PJ (2013) E3 ubiquitin ligase-mediated regulation of bone formation and tumorigenesis. Cell Death Dis 4: e463.

18. Edwin F, Patel TB (2008) A novel role of Sprouty 2 in regulating cellular apoptosis. J Biol Chem 283: 3181-3190.

19. Yan SC, Liu YP, Zhang LY, Qu JL, Xu L, et al. (2011) Ubiquitin ligase c-Cbl is involved in tamoxifen-induced apoptosis of MCF-7 cells by downregulating the survival signals. Acta Oncol 50: 693-699.

20. Qu J, Zhao M, Teng Y, Zhang Y, Hou K, et al. (2011) Interferon-Ît sensitizes human gastric cancer cells to TRAlL-induced apoptosis via activation of the C-CBL-dependent MAPK/ERK pathway. Cancer Biol Ther 12: 494-502.

21. Fulda S (2009) Tumor resistance to apoptosis. Int J Cancer 124: 511-515.

22. Isaacs JT (2000) Apoptosis: translating theory to therapy for prostate cancer. J Natl Cancer Inst 92: 1367-1369.

23. Knight JF, Shepherd CJ, Rizzo S, Brewer D, Jhavar S, et al. (2008) TEAD1 and $\mathrm{c}-\mathrm{Cbl}$ are novel prostate basal cell markers that correlate with poor clinical outcome in prostate cancer. Br J Cancer 99: 1849-1858. 
Citation: Yakoub S, El-Chami N, Kaszas K, Malek M, El Sirkasi M, et al. (2014) The Proto-Oncoprotein c-Cbl Protects Cells against Oxidative Stress by Down-Regulating Apoptosis and is Highly Expressed in Several Cancers. J Cancer Sci Ther 6: 122-135. doi:10.4172/1948-5956.1000260

24. Naramura M, Kole HK, Hu RJ, Gu H (1998) Altered thymic positive selection and intracellular signals in Cbl-deficient mice. Proc Natl Acad Sci U S A 95: $15547-15552$.

25. Goldberg MP, Strasser U, Dugan LL (1997) Techniques for assessing neuroprotective drugs in vitro. Int Rev Neurobiol 40: 69-93.

26. Tessarollo L (2001) Manipulating mouse embryonic stem cells. Methods Mol Biol 158: 47-63.

27. Todaro GJ, Green H (1963) Quantitative studies of the growth of mouse embryo cells in culture and their development into established lines. J Cell Bio 17: 299-313.

28. Manin M, Baron S, Goossens K, Beaudoin C, Jean C, et al. (2002) Androgen receptor expression is regulated by the phosphoinositide 3-kinase/Akt pathway in normal and tumoral epithelial cells. Biochem J 366: 729-736.

29. Banerjee PP, Banerjee S, Brown TR (2002) Bcl-2 protein expression correlates with cell survival and androgen independence in rat prostatic lobes. Endocrinology 143: 1825-1832.

30. Omezzine A, Mauduit C, Tabone E, Nabli N, Bouslama A, et al. (2003) Caspase- 3 and -6 expression and activation are targeted by hormone action in the rat ventral prostate during the apoptotic cell death process. Biol Reprod 69: $752-760$

31. Wiggins CM, Band $\mathrm{H}$, Cook SJ (2007) c-Cbl is not required for ERK1/2dependent degradation of BimEL. Cell Signal 19: 2605-2611.

32. Molero JC, Jensen TE, Withers PC, Couzens M, Herzog H, et al. (2004) $\mathrm{c}$-Cbl-deficient mice have reduced adiposity, higher energy expenditure, and improved peripheral insulin action. J Clin Invest 114: 1326-1333.

33. Molero JC, Waring SG, Cooper A, Turner N, Laybutt R, et al. (2006) Casitas b-lineage lymphoma-deficient mice are protected against high-fat diet-induced obesity and insulin resistance. Diabetes 55: 708-715

34. Dong Q, Liu YP, Qu XJ, Hou KZ, Li LL (2010) [Expression of c-Cbl, Cbl-b and epidermal growth factor receptor in gastric carcinoma and their clinical significance]. Chin J Cancer 29: 59-64.

35. Tan YH, Krishnaswamy S, Nandi S, Kanteti R, Vora S, et al. (2010) CBL is frequently altered in lung cancers: its relationship to mutations in MET and EGFR tyrosine kinases. PLoS One 5: e8972.

36. Sanada M, Suzuki T, Shih LY, Otsu M, Kato M, et al. (2009) Gain-of-function of mutated C-CBL tumour suppressor in myeloid neoplasms. Nature 460: $904-$ 908

37. Tefferi A (2010) Novel mutations and their functional and clinical relevance in myeloproliferative neoplasms: JAK2, MPL, TET2, ASXL1, CBL, IDH and IKZF1. Leukemia 24: 1128-1138.

38. Rathinam C, Thien CB, Flavell RA, Langdon WY (2010) Myeloid leukemia development in C-CbI RING finger mutant mice is dependent on FLT3 signaling. Cancer Cell 18: 341-352.

39. Kumar B1, Koul S, Khandrika L, Meacham RB, Koul HK (2008) Oxidative stress is inherent in prostate cancer cells and is required for aggressive phenotype. Cancer Res 68: 1777-1785

40. Harris JL, Jakob B, Taucher-Scholz G, Dianov GL, Becherel OJ, et al. (2009)
Aprataxin, poly-ADP ribose polymerase 1 (PARP-1) and apurinic endonuclease 1 (APE1) function together to protect the genome against oxidative damage. Hum Mol Genet 18: 4102-4117.

41. Matsuzawa A, Ichijo $H$ (2008) Redox control of cell fate by MAP kinase: physiological roles of ASK1-MAP kinase pathway in stress signaling. Biochim Biophys Acta 1780: 1325-1336

42. Kamata H, Hirata H (1999) Redox regulation of cellular signalling. Cell Signal 11: 1-14.

43. Leslie NR, Bennett D, Lindsay YE, Stewart H, Gray A, et al. (2003) Redox regulation of PI 3-kinase signalling via inactivation of PTEN. EMBO J 22: 5501 5510.

44. Ravid T, Sweeney C, Gee P, Carraway KL 3rd, Goldkorn T (2002) Epidermal growth factor receptor activation under oxidative stress fails to promote $\mathrm{c}-\mathrm{Cb}$ mediated down-regulation. J Biol Chem 277: 31214-31219.

45. Echtay KS, Roussel D, St-Pierre J, Jekabsons MB, Cadenas S, et al. (2002) Superoxide activates mitochondrial uncoupling proteins. Nature 415: 96-99.

46. Vander Heiden MG, Cantley LC, Thompson CB (2009) Understanding the Warburg effect: the metabolic requirements of cell proliferation. Science 324 1029-1033.

47. Ruckenstuhl C, Büttner S, Carmona-Gutierrez D, Eisenberg T, Kroemer G, et al. (2009) The Warburg effect suppresses oxidative stress induced apoptosis in a yeast model for cancer. PLoS One 4: e4592.

48. Denmeade SR, Lin XS, Isaacs JT (1996) Role of programmed (apoptotic) cell death during the progression and therapy for prostate cancer. Prostate 28: 251265.

49. Krajewska M, Krajewski S, Banares S, Huang X, Turner B, et al. (2003) Elevated expression of inhibitor of apoptosis proteins in prostate cancer. Clin Cancer Res 9: 4914-4925.

50. Corsois L, Quatannens B, Dumont P, Aumercier M, Defresne MP, et al. (2002) Association of a new c-Cbl related protein with the very first stages of apoptosis induction. Cancer Detect Prev 26: 93-104.

51. Denis G, Mandard S, Humblet C, Verlaet M, Boniver J, et al. (1999) Nuclear localization of a new c-cbl related protein, CARP 90 , during in vivo thymic apoptosis in mice. Cell Death Differ 6: 689-697.

52. Bonaccorsi L, Nosi D, Muratori M, Formigli L, Forti G, et al. (2007) Altered endocytosis of epidermal growth factor receptor in androgen receptor positive prostate cancer cell lines. J Mol Endocrinol 38: 51-66.

53. Lo FY, Tan YH, Cheng HC, Salgia R, Wang YC (2011) An E3 ubiquitin ligase: c-Cbl: a new therapeutic target of lung cancer. Cancer 117: 5344-5350.

54. Ito R, Nakayama H, Yoshida K, Matsumura S, Oda N, et al. (2004) Expression of $\mathrm{Cbl}$ linking with the epidermal growth factor receptor system is associated with tumor progression and poor prognosis of human gastric carcinoma. Virchows Arch 444: 324-331.

55. Kokontis JM, Hay N, Liao S (1998) Progression of LNCaP prostate tumor cells during androgen deprivation: hormone-independent growth, repression of proliferation by androgen, and role for p27Kip1 in androgen-induced cell cycle arrest. Mol Endocrinol 12: 941-953. 